\title{
Standardized herbal extract PM014 alleviates fine dust-induced lung inflammation in mice
}

\author{
Ye-Seul Lee ${ }^{1 \dagger}$, Daeun Min ${ }^{2 \dagger}$, Seon-Young Park ${ }^{2}$, Junyoung Lee ${ }^{2}$ and Hyunsu Bae ${ }^{2^{*}}$ (D)
}

\begin{abstract}
Background: Fine dust penetrates deep into the human alveoli, and the fine dust accumulated in the bronchus and lungs can directly trigger various respiratory diseases. PM014 (HL301) is the herbal extract derived from the herbal medicine Chung-Sang-Bo-Ha-Tang which is used for the treatment of lung diseases.

Methods: To evaluate the effect of PM014 on the lung inflammation induced by fine dust, this study investigated inflammatory responses in the lung upon pm10 exposure by examining the infiltration of inflammatory cell profiles from bronchial alveolar lavage fluid (BALF), lung histology, and production of pro-inflammatory cytokines measured by RT-PCR and ELISA.

Results: PM014-treated mice exhibited reduced lung tissue damage and inflammatory cell infiltration. Bronchoalveolar lavage fluid (BALF) analysis showed significant decrease in the population of total cells, macrophages, eosinophils, and neutrophils in PM014-treated mice. PM014 treatment downregulated the proinflammatory cytokine expressions including IL-1b, IL-8, IL-6, TNF-alpha, IL-21 and IL-17. ELISA analysis also showed reduced production of IL-1b, IL-6 and IL-17 in PM014-treated mice.

Conclusion: PM014 suppressed the pm10-induced inflammatory response in mice. This study shows that PM014 is a possible therapeutic agent for lung inflammation induced by fine dust.
\end{abstract}

Keywords: pm10, Fine dust, PM014, Chung-sang-Bo-ha-tang, BALF

\section{Background}

Fine dust, or Particulate Matter 10 (pm10), is defined as inhalable particles with a diameter of less than $10 \mu \mathrm{m}$ according to the United States Environmental Protection Agency. These particles vary in size and shape and consist of hundreds of different chemicals. Some are emitted directly from sources such as construction sites, unpaved roads, chimneys, and fires. However, most form in the atmosphere as a result of complex reactions of chemicals

\footnotetext{
* Correspondence: hbae@khu.ac.kr

${ }^{\dagger}$ Ye-Seul Lee and Daeun Min contributed equally to this work. 2 Department of Physiology, College of Korean Medicine, Kyung Hee University, 26-6 Kyungheedae-ro, Dongdaemoon-gu, Seoul 02453, Republic of Korea

Full list of author information is available at the end of the article
}

such as sulfur dioxide, nitrogen oxides, lead, ozone, carbon monoxide, and pollutants emitted by power plants, industries, and automobiles. It is possible that particle size is linked to the potential for health problems, the biggest problem being that small particles less than $10 \mu \mathrm{m}$ in diameter can get deep into the lungs and enter the bloodstream. Exposure to these particles can affect both the lungs and the heart. Numerous scientific studies show that particle contamination exposure is associated with a variety of problems such as exacerbation of asthma, decrease in lung function, airway irritation, coughing, and difficulty breathing [1].

PM014 (HL301) is a standardized formulation of Chung-Sang-Bo-Ha-Tang (CSBHT) which has shown to

(c) The Author(s). 2020 Open Access This article is licensed under a Creative Commons Attribution 4.0 International License, which permits use, sharing, adaptation, distribution and reproduction in any medium or format, as long as you give appropriate credit to the original author(s) and the source, provide a link to the Creative Commons licence, and indicate if changes were made. The images or other third party material in this article are included in the article's Creative Commons licence, unless indicated otherwise in a credit line to the material. If material is not included in the article's Creative Commons licence and your intended use is not permitted by statutory regulation or exceeds the permitted use, you will need to obtain permission directly from the copyright holder. To view a copy of this licence, visit http://creativecommons.org/licenses/by/4.0/ The Creative Commons Public Domain Dedication waiver (http://creativecommons.org/publicdomain/zero/1.0/) applies to the data made available in this article, unless otherwise stated in a credit line to the data. 
be effective in treating lung diseases through a number of animal studies. Its original formula, CSBHT, is a medication with 18 herbs that has been used in Korea to treat chronic lung diseases such as asthma [2]. As there are 18 herbs in CSBHT, which make it difficult to standardize, the herbal formula has been modified to 7 herbs and standardized into herbal formulation named PM014 (Table 1). Our previous study demonstrates the anti-inflammatory effect of PM014 on radiation-induced pulmonary inflammation in a murine model [3]. In vitro and in vivo results from other studies shows a similar effect of PM014 in murine models of chronic obstructive pulmonary disease (COPD) $[4,5]$ and cockroach allergen-induced asthma [6]. In addition, PM014 has recently been shown to improve pulmonary fibrosis induced by bleomycin [7]. Furthermore, a thirteen-week study of PM014 showed no subchronic oral toxicity in animal model, providing supportive evidence of the safety of PM014. Taken together, PM014 is a safe and effective herbal formulation which can be applied to chronic and subchronic inflammation in the lungs.

From the aforementioned anti-inflammatory effects of PM014 in various models of lung diseases, this study hypothesized that PM014 will alleviate lung inflammation induced by fine dust. We tested this hypothesis by investigating the effect of PM014 on a pm10-induced lung inflammation mouse model. The results showed that PM014 was effective via immunological changes, such as reduced inflammatory cytokines and histopathological changes in the lung tissue in the pm10-induced pulmonary inflammation mouse model.

\section{Methods}

\section{Animals}

Seven-week-old female C57BL/6 mice were purchased from Taconic Korea (DBL, Chungbuk, Korea). All animals were housed in a controlled environment (12/12 h light/dark cycle; $22 \pm 1^{\circ} \mathrm{C}$ ) and had ad libitum access to food and water. This study was approved by the Kyung Hee University Animal Care and Use Committee. All experiments were performed according to regional

Table 1 Components of PM014

\begin{tabular}{lll}
\hline Formula of PM014 & Amount (g) & Chemical marker \\
\hline Root of Rehmannia glutinosa (RG) & 600 & 5-HMF \\
Cortex of Paeonia suffruticosa (PS) & 300 & Paeoniflorin \\
Fruit of Schizandra chinensis (SC) & 300 & Schizandrin \\
Root of Asparagus cochinchinensis (AC) & 300 & Asparagine \\
Seed of Prunus armeniaca (PA) & 225 & Amygdalin \\
Root of Scutellaria baicalensis (SB) & 225 & Baicalin \\
Root of Stemona sessilifolia (SS) & 150 & Stemonine \\
Total & $2100 \mathrm{~g}$ & \\
\hline
\end{tabular}

guidelines established by Kyung Hee University [KHUASP (SE) 19-007].

\section{Preparation of fine dust}

Fine dust (ERM-CZ120) that consisted of arsenic, cadmium, lead, and nickel was purchased from the Institute for Reference Materials and Measurements (Geel, Belgium). This contained $0.5 \mathrm{~g}$ of fine dust that was processed to resemble pm10. This was packed into amber glass vials and closed with a rubber stopper and aluminum cap under an argon atmosphere. The mass fraction of the elements of fine dust used in this experiment is presented in Table 2.

\section{Preparation of PM014}

The components of PM014 were purchased from Kyung Hee Herb Pharm (Seoul, South Korea) and prepared by Hanlim Pharm Co. LTD (Yongin, Korea) as described in a previous studies $[3,7]$. The preparation of the medicinal herbs was based on the standards provided by The Korean Herbal Pharmacopoeia published by the Korean Food and Drugs Administration (KFDA). As Prunus armeniaca, of which the seed was used in the preparation of PM014, is classified as endangered by the International Union for Conservation of Nature (IUCN), the use of this plant was limited to minimum for the research purposes only. Process of the preparation of PM014 was done in compliance with the IUCN Policy Statement on Research Involving Species at Risk of Extinction.

Each herb was cut, mixed, dissolved, and extracted using a reflux condenser at $90-100{ }^{\circ} \mathrm{C}$ for $3 \mathrm{~h}$ and then filtered using a $25-\mu \mathrm{m}$ sieve. This produced $2100 \mathrm{~g}$ of substance according to the ratios indicated in Table 1. Undesirable materials were removed by filtration (Sigma, St. Louis, MO, USA). The solvent was concentrated at

Table 2 Composition and mass fraction (certified value and uncertainty) of pm10-like fine dust

FINE DUST (pm10-LIKE)

\begin{tabular}{|c|c|c|}
\hline \multirow[t]{2}{*}{ Element } & \multicolumn{2}{|l|}{ Mass Fraction } \\
\hline & Certified value $^{1)}[\mathrm{mg} / \mathrm{kg}]$ & Uncertainty $^{2)}[\mathrm{mg} / \mathrm{kg}]$ \\
\hline Arsenic & 7.1 & 0.7 \\
\hline Cadmium & 0.90 & 0.22 \\
\hline Lead & 113 & 17 \\
\hline Nickel & 58 & 7 \\
\hline \multicolumn{3}{|c|}{$\begin{array}{l}\text { 1) Unweighted mean value of the means of accepted sets of data, each set } \\
\text { being obtained in a different laboratory and/or with a different method. The } \\
\text { certified values and their uncertainties are mass fractions based on the mass } \\
\text { of the sample after conditioning as described in EN12341 standard of the } \\
\text { European Committee for Standardization } \\
\text { 2) The certified uncertainty is the expanded uncertainty with a coverage factor } \\
k=2 \text { corresponding to a level of confidence of about } 95 \% \text { estimated in } \\
\text { accordance with ISO/IEC Guide } 98-3 \text {, Guide to the Expression of Uncertainty in } \\
\text { Measurement (GUM: 1995), ISO, } 2008\end{array}$} \\
\hline
\end{tabular}


$60{ }^{\circ} \mathrm{C}$ using an evaporator under vacuum, and the final product of PM014 was collected in the form of dried extract powder [7]. PM014 $(20 \mathrm{mg} / \mathrm{ml})$ was dissolved in high-performance liquid chromatography (HPLC)-grade methanol and filtered using Minisart RC15 (Sartorius Stedim Biotech, Germany). In the experiment, PM014 was further diluted for administration using phosphatebuffered saline (PBS) at different concentrations. In the final PM014 extract, the quantities of standard materials per $1 \mathrm{~g}$ were paeoniflorin $>0.43 \mathrm{mg}$, schizandrin $>0.12$ $\mathrm{mg}$, baicalin $>7.26 \mathrm{mg}$, and amygdalin $>2.48 \mathrm{mg}$. Highperformance liquid chromatography analysis was performed to quantify the standard materials of PM014. Three independent data were produced for the analysis from three independent batches of each compound. The standardized formula of PM014 was approved by the Ministry of Food and Drug Safety, Republic of Korea for the Investigational New Drug (IND) program (ID: 20130030575). The voucher specimen of this material has been deposited in Hanlim Pharm, Co. LTD, and the deposition number is PURI 15004.

\section{Fine dust (pm10)-induced lung inflammation mouse model}

Fine dust $(100 \mu \mathrm{g} / \mathrm{ea})$ was used to induce lung inflammation in mice. Female $\mathrm{C} 57 \mathrm{BL} / 6$ mice were randomly divided into six groups: control, pm10 group, pm10 + PM014 group, and pm10 + DEXA (dexamethasone, 10 $\mathrm{mg} / \mathrm{kg}$ ). The most efficient concentration of PM014 to elicit inhibitory effects on lung inflammation was investigated in our previous study to be a dose of $200 \mathrm{mg} / \mathrm{kg}$ [3]. For the evaluation of different doses used in this study those administered therapeutically, we referred to the guidance for industry prepared by the Office of New Drugs in the Center for Drug Evaluation and Research at the Food and Drug Administration [3, 8]. The optimal timing for the administration of PM014 was applied based on another preliminary experiment [7], and we decided to use continual treatment of PM014 to examine the significant impact on fine dust-induced inflammation. Both PM014 and DEXA were administered orally (peroral administration, p.o.).

In the pm10+PM014 group, the dose of PM014 were different across three subgroups: 50, 100, or $200 \mathrm{mg} / \mathrm{kg}$. On days 0, 2, 7, and 9, mice were lightly anesthetized with isoflurane and tested for a prophylactic effect by intratracheal administration of pm10 dissolved in $50 \mu \mathrm{l}$ of PBS $2 \mathrm{~h}$ after oral administration of PM014. On days 5 and 12, only PM014 was administered without injecting fine dust. pm10 was given twice a week and PM014 was given three times a week. On day 14, all mice were euthanized and harvested to analyze the lungs.

\section{Analysis of bronchoalveolar lavage fluid}

During intrathecal (IT) injection, wet paper towel with isoflurane $(100 \mathrm{ul})$ was placed underneath the wire mesh in the anesthesia glass jar $(500 \mathrm{ml})$ to prevent direct contact of animal with the isoflurane. Mouse was placed in the jar for $1 \mathrm{~min}$ with the lid closed. Euthanasia was performed with mice placed in the glass jar $(500 \mathrm{ml})$ with an overdose isoflurane $(250 \mathrm{ul})$ per mouse for 5 min. During euthanasia, mice were constantly observed to check their breathing. After all of the animals were euthanized, bronchial alveolar lavage fluid (BALF) was collected by washing the lungs three times with $1 \mathrm{ml}$ of PBS. BALF samples were centrifuged at $2000 \mathrm{rpm}$ for 10 min at $4{ }^{\circ} \mathrm{C}$ and the cell pellet was resuspended in $1 \mathrm{ml}$ of PBS [7]. A hemocytometer was used to count the total number of live immune cells. The cells were then cytospun onto microscope slides and stained with the Diff-Quick Staining Kit (Thermo Fisher Scientific, Waltham, MA, USA). Cells (500 per slide) were counted under an optical microscope $[3,7]$.

\section{Histopathological staining}

The left lung was isolated from the mouse and immediately fixed with $4 \%$ paraformaldehyde before serial tissue processing and embedding with paraffin wax. For histological studies, tissues were cut into $5 \mu \mathrm{m}$ sections using a microtome, and deparaffinized tissue sections were stained with eosin and hematoxylin ( $\mathrm{H} \& \mathrm{E}$, Sigma, St. Louis, MO, USA) before mounting to evaluate the morphological changes in the lungs.

\section{Quantitative real-time PCR}

Total RNA was extracted from lung tissues and cells using Easy Blue ${ }^{\mathrm{Ts}}$ (Intron Company, Seongnam, Korea). The first-strand cDNA was synthesized using a cDNA synthesis kit (Bioneer Corporation, Daejeon, Korea). Subsequently, mRNA levels of tumor necrosis factor- $\alpha$ (TNF- $\alpha$ ), interleukin (IL)-1 $\beta$, IL-6, IL-8, interferon- $\gamma$ (IFN- $\gamma)$, monocyte chemoattractant protein 1 (MCP-1), IL-17, IL-21, and IL-23 were determined using LightCycler 96 (Roche, Basel, Switzerland) along with SYBR Green qPCR Mastermix (Bioline Reagents Ltd., London, United Kingdom). Relative levels of mRNA expression in $20 \mu \mathrm{l}$ were normalized to the expression of $\beta$-actin for each gene.

\section{ELISA}

Protein concentration of the lung was determined using the albumin standard (Thermo Fisher Scientific, Waltham, MN, U.S.A). To measure cytokine concentration of lungs, sandwich enzyme-linked immunosorbent assay (ELISA) was conducted. IL-1b, IL-6, and IL-17 DuoSet ELISA (R\&D System, Minneapolis, MN, U.S.A) were used in this experiment according to the 
manufacturer's protocol. Optical density was measured at $450 \mathrm{~nm}$ by using a microplate reader.

\section{Statistical analysis}

Statistical analysis was performed using Prism 5 software (Graph Pad Software Inc., San Diego, CA, USA). Data were represented as means \pm SEM. A one-way analysis of variance (ANOVA), followed by the Newman-Keuls test, was performed. $P<0.05$ was considered statistically significant.

\section{Results}

Effect of PM014 on pm10-induced histological changes in lung tissue

Histopathological changes and inflammatory responses due to pm10-induced lung injury in PM-treated mice showed the accumulation of multiple inflammatory cells in alveolar spaces after 2 weeks. Alveolar infiltration by inflammatory cells in the PM group was significantly higher than that in the control group. However, PM014treated mice showed reduced tissue damage, which included less inflammatory cell infiltration in the alveoli (Fig. 1a and b), compared to the control group.

\section{Effect of PM014 on inflammatory cell infiltration in the} lungs

The total cell count of BALF in the PM group was significantly higher than that in the control group (Fig. 2a). In the PM group, macrophages (Fig. 2b), neutrophils (Fig. 2c), eosinophils (Fig. 2d), and lymphocytes (Fig. 2e) were significantly higher than in the control group. In contrast, the population of total cells, macrophages, neutrophils, and eosinophils in PM014-treated mice was significantly lower than that in PM-treated mice.

\section{Effect of PM014 on inflammation-related gene expression in the lungs}

The expression of cytokines IL-1b, IL-8, and IL-17 (Fig. 3a, c, and g) was significantly higher in the PMtreated mice than that in the control group. However, treatment with PM014 reduced the expression of these cytokines. The rest of the cytokines and chemokines did not increase significantly in the PM-treated mice, but the levels of these cytokines and chemokines in the group treated with PM014 showed a tendency to decrease in comparison to the PM group (Fig. 3b, d-f, h, and i).

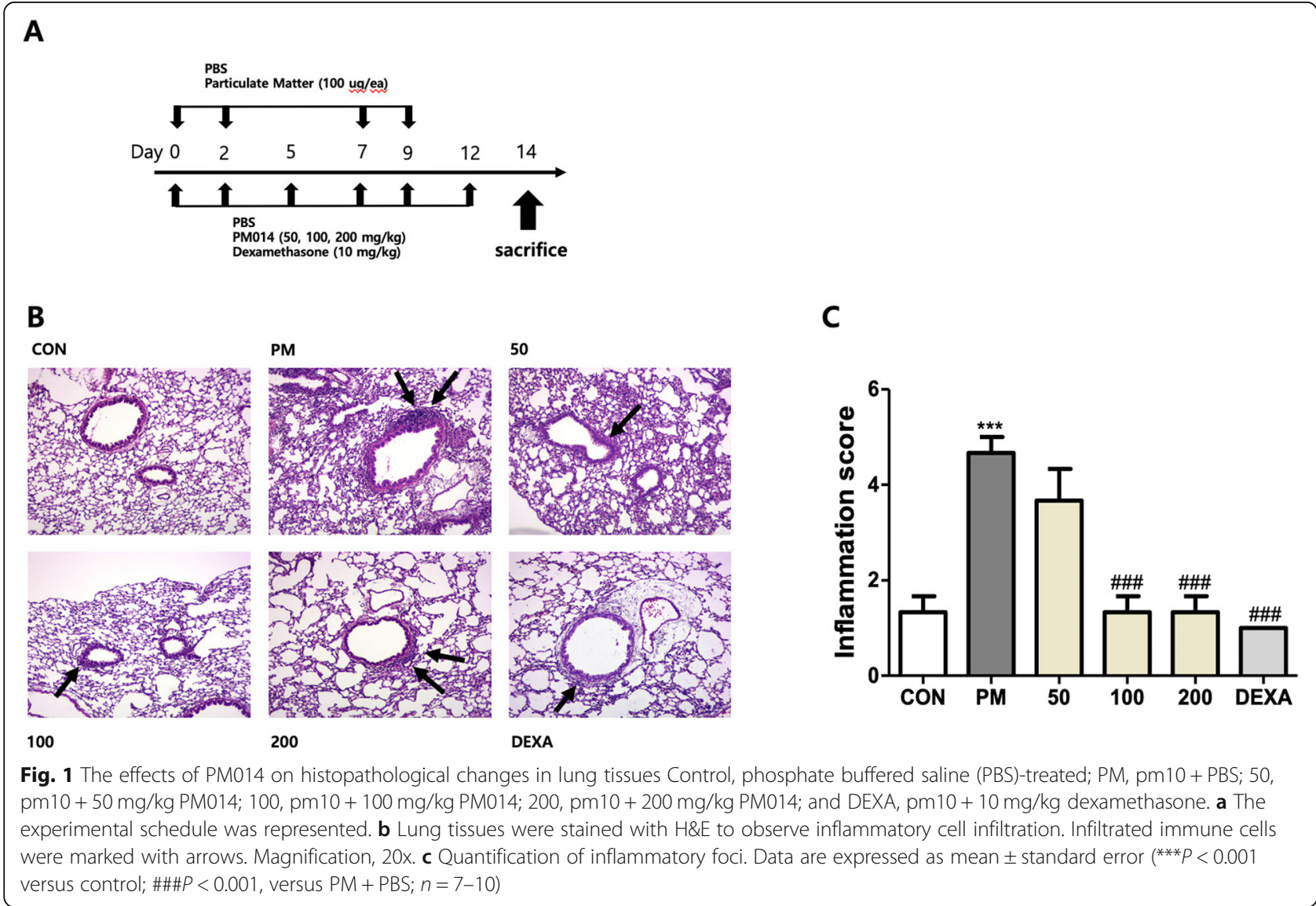




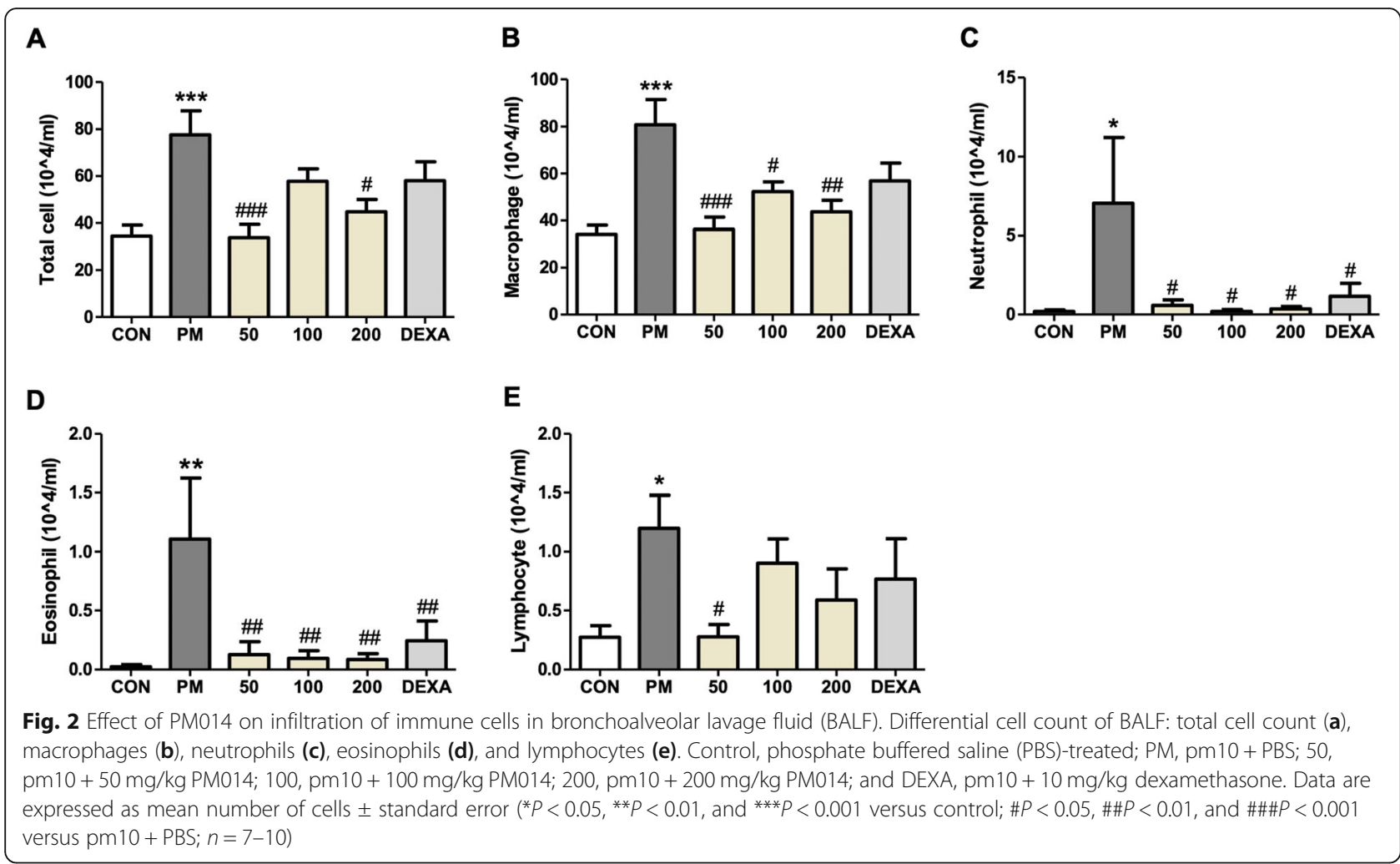

\section{Effect of PM014 on inflammation-related cytokine production in the lungs}

ELISA was used to measure inflammation-related cytokine production of lungs. In Fig. 4(a-c), the amount of IL-1b, IL-6, and IL-17 was significantly higher in the PM-treated mice than that in the control group. DEXA group showed a tendency to decrease in comparison to the PM-treated group. However, treatment with $200 \mathrm{mg} /$ kg PM014 reduced significantly amount of these cytokines.

\section{Discussion}

pm10, a type of fine dust with inhalable particles and typically less than $10 \mu \mathrm{m}$ in diameter, is increasingly diffusing into the atmosphere and emerging as a threat to the health of those who breathe in air with pm10 [1]. The related health problems are mainly due to its small size, specifically because particles less than $10 \mu \mathrm{m}$ in diameter can go deep into the lungs and into the bloodstream [9]. Exposure to pm10 can affect both the lungs and the heart, which causes inflammation in the lungs and cardiac rhythm abnormalities. A number of previous studies show that particle contamination exposure is associated with a variety of problems such as exacerbation of asthma, decrease in lung function, airway irritation, coughing, and difficulty breathing [10-13]. Therefore, this study investigated how PM014, a herbal formula that has previously been shown to relieve symptoms related to the lungs such as asthma and COPD [2-4, 7], affects fine dust-induced lung inflammation in a fine dust-induced acute lung injury mouse model. This preventive effect of PM014 on fine dust-related diseases may have an important implication in the future as the impact of fine dust is becoming both substantial and unavoidable.

CSBHT is a herbal formula well-known for the treatment of lung diseases in Korean Medicine, and PM014 in this study is a standardized herbal formula with seven herbs extracted from CSBHT [6]. We had investigated the effect of PM014 in comparison with the effects of individual ingredient herbs using an acute lipopolysaccharide-induced lung injury model, which showed a greater reduction of immune cell infiltration in the lungs with the treatment of PM014 [3, 4]. In this study, the reduction of immune cell infiltration in the lungs due to PM014 was greater than that from treatment with individual herbs. A preliminary experiment which aimed to identify the optimal dosage of PM014 was performed with different doses of 50, 100, 200, and $300 \mathrm{mg} / \mathrm{kg}$, and the result showed that $200 \mathrm{mg} / \mathrm{kg}$ is the most efficient [3]. In this study, we referred to the guidance for industry prepared by the Office of New Drugs in the Center for Drug Evaluation and Research at the Food and Drug Administration for the evaluation of the doses in comparison with the doses that were administered therapeutically $[3,8]$. According to this guidance, 


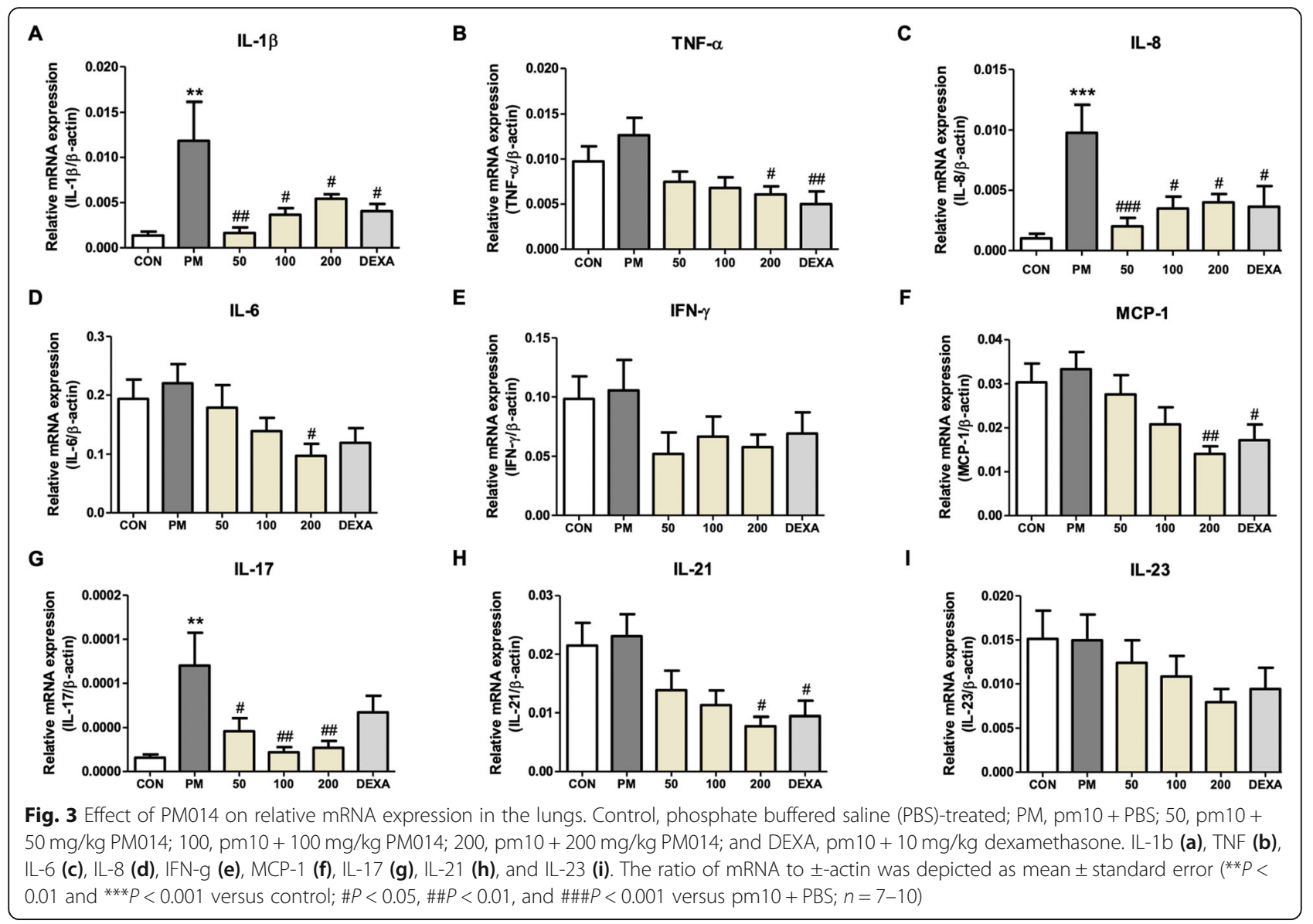

treatment with $200 \mathrm{mg} / \mathrm{kg}$ of PM014 in a mouse model implies that $1 \mathrm{~g}$ of PM014 is equivalent to the dose in a $60 \mathrm{~kg}$ human. Furthermore, another preliminary experiment was performed to discover the optimal timing for the administration of PM014, in which a single treatment for 1 week and continual treatment for three times a week of PM014 was compared [7]. This experiment showed that treatment once a week did not have significant effects; therefore, we decided to use continual treatment, rather than a single treatment, of PM014 to examine the significant impact on fine dust-induced inflammation.

Although the mechanism of the lung inflammatory response from pm10 is unclear, studies on the impact of pm10 on lung inflammation show decrease in microvascular function and increase in leukocyte, neutrophil, and eosinophil counts [14]. We previously reported the mechanism of the protective effects in the lungs exerted by PM014, which in vitro showed that PM014 led to the inhibition of TGF- $\beta 1$-induced epithelial-mesenchymal

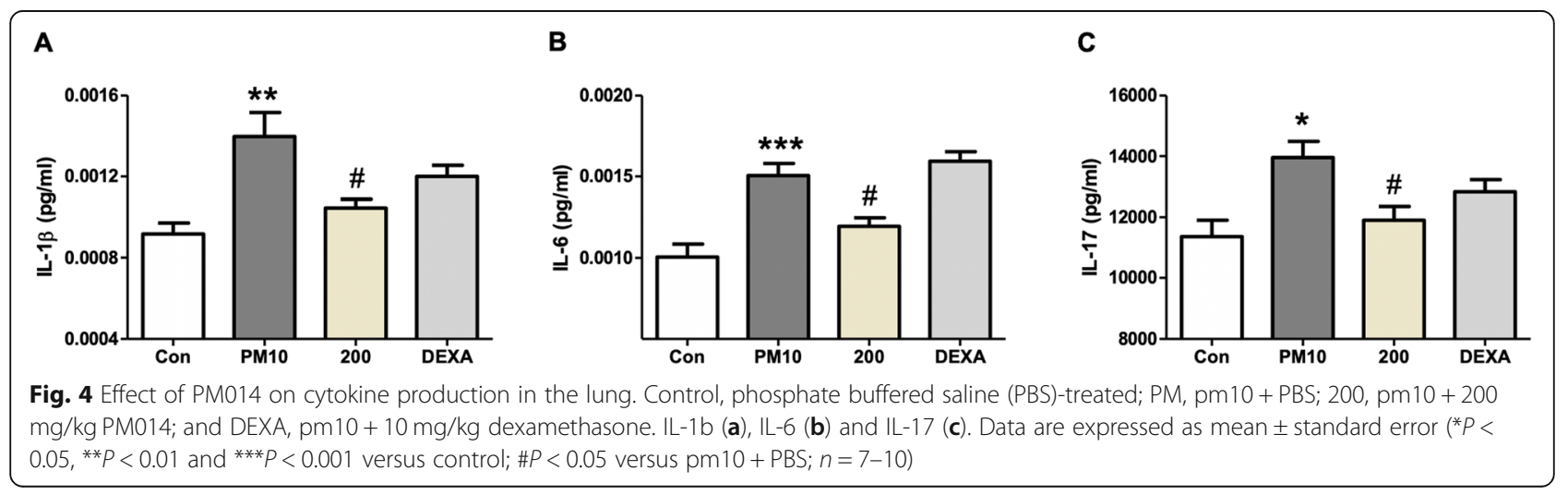


transition (EMT) and fibroblast activation in alveolar epithelial cells and human lung fibroblasts [3, 7]. This study showed that TGF- $\beta 1$ signaling via $\mathrm{p} 38$ mitogen-activated protein kinases (MAPKs) pathways and Smad-dependent pathways were the main targets of PM014. Furthermore, PM014 treatment led to the downregulation of inflammatory cytokines, chemokines, and fibrosis-related genes, and reduction in the growth of factor- $\beta 1$-positive cell population in lung tissue $[3,7,15]$.

Our study showed a consistent result with respect to the influence of pm10 on lung function and showed an increased level of macrophages, neutrophils, eosinophils, and lymphocytes. Furthermore, in our study, pm10 induced increased levels of IL- $1 \beta$, IL-8, and IL-17. Previous studies show that IL-8 dependent inflammation implies innate immunity of the lung to bacterial pathogens, as well as chronic lung inflammation and impaired function that are progressive and irreversible, such as chronic obstructive pulmonary disease (COPD), bronchiectasis, and pulmonary fibrosis [16]. An elevated level of IL-1 $\beta$ indicates pulmonary inflammation, emphysema, and airway remodeling and is increased in the lungs of patients with COPD and asthma [17]. Lastly, IL-17 promotes skin and lung inflammation [18]. Overall, in our study, pm10 caused lung inflammation in mice that led to chronic and irreversible changes in lung function.

This study assessed the effect of PM014 on tissue inflammatory responses, in specific on the immune cell infiltration and cytokine expression, 2 weeks after the start of the experiment. Although fine dust, represented by pm10 in our study, caused lung inflammation, PM014 treatment led to a significant decrease in immune cell infiltration around the bronchioles (Figs. 1 and 2). During inflammatory reactions, inflammatory cells including macrophages, neutrophils, fibroblasts, and lymphocytes are activated, leading to the release of inflammatory and fibrotic cytokines [19]. Our results showed that PM014 treatment significantly reduced inflammatory cell infiltration in BALF (Fig. 2), which implied a significant reduction in the population of macrophages. These results suggest that the main attribute of the anti-inflammatory effect of PM014 may be the inhibition of the activation of macrophages.

Furthermore, our discoveries are consistent with an earlier report in which PM014 blocked the inflammatory cells influx and decreased pro-inflammatory cytokines in mice $[4,7]$. In this study, exposure to pm10 increased the inflammatory cells infiltration and production of pro-inflammatory cytokines on day 14 . Proinflammatory cytokines including IL-8, IL-1 $\beta$, and IL-17 were released from the inflammatory cells. On the other hand, daily administration of PM014 was proven to be effective in the prevention of the secretion of cytokines due to pm10 [7]. No significant difference was observed in the expression levels of other cytokines such as IL-6, IL-21, IL-23, and TNF between pm10 mice and control mice. IL-23 acts as a regulator that promotes the development of IL-17-producing helper $\mathrm{T}$ cells [20]. In addition to this knowledge, recent studies show that not only the Th17 cells, but also other cells such as $\mathrm{CD} 8^{+} \mathrm{T}$ cells and neutrophils produce IL-17 [21], which calls for a further investigation on the role of $\mathrm{T}$ cells in the immune responses in the lungs. Overall, our results suggest that PM014 alleviates lung inflammation induced by pm10 via reduction of pro-inflammatory cytokines, which are produced by the inflammatory cells. Future studies that explore how PM014 directly plays the role of an anti-inflammatory substance in lung inflammation due to pm10 may provide further information on the mechanism of the therapeutic effects of PM014.

\section{Conclusion}

Fine dust is an air pollutant that contains chemicals such as sulfuric acid gas and nitrogen oxides that are generated in power plants, automobiles, and factories. Fine dust, also known as PM, penetrates deep into the human alveoli and the fine dust accumulated in the bronchus, and lungs can directly trigger various respiratory diseases and reduce immune function. PM014 is a herbal extract derived from the herbal medicine CSBHT, which is used for the treatment of lung diseases in traditional medicine. In this study, we observed that fine dust increased the infiltration of inflammatory cells in the lungs of mice. The expression of pro-inflammatory cytokines was measured by RT-PCR and PM014-treated mice exhibited reduced tissue damage, inflammatory cell infiltration, and pro-inflammatory cytokine gene expression. Our study showed that the administration of PM014 suppressed the pm10-induced inflammatory response in mice.

\section{Abbreviations}

pm10: Particulate Matter 10; BALF: Bronchial alveolar lavage fluid; CSBHT: Chung-Sang-Bo-Ha-Tang; COPD: Chronic obstructive pulmonary disease; PBS: Phosphate buffered saline

\section{Acknowledgements}

Not applicable.

\section{Authors' contributions}

Conceptualization, SYP and HB; Data acquisition, DM, SYP, and JYL; Funding acquisition, HB; Investigation, DM, SYP, JYL and YSL; Data analysis, DM and YSL; Supervision, HB; Writing - Original Draft Preparation, DM and YSL; Writing - Review \& Editing, YSL and HB. All authors have read and approved the manuscript.

\section{Funding}

This research was supported by grants from the National Research Foundation of Korea (NRF) funded by the Korea government (NRF2020R1A2B5B03002164). The funding body had no role in the design of the study and collection, analysis, and interpretation of data and in writing the manuscript. 


\section{Availability of data and materials}

The datasets used and/or analysed during the current study are available from the corresponding author on reasonable request.

\section{Ethics approval and consent to participate}

This study was approved by the Kyung Hee University Animal Care and Use Committee. All experiments were performed according to regional guidelines established by Kyung Hee University [KHUASP (SE) 19-007].

\section{Consent for publication}

Not applicable.

\section{Competing interests}

All of the authors declare that no competing interests exist.

\section{Author details}

'Department of Anatomy and Acupoint, College of Korean Medicine, Gachon University, Seongnam 13120, South Korea. ${ }^{2}$ Department of Physiology, College of Korean Medicine, Kyung Hee University, 26-6 Kyungheedae-ro, Dongdaemoon-gu, Seoul 02453, Republic of Korea.

Received: 24 November 2019 Accepted: 25 August 2020

Published online: 07 September 2020

\section{References}

1. Lee YG, Ho C-H, Kim J-H, Kim J. Quiescence of Asian dust events in South Korea and Japan during 2012 spring: dust outbreaks and transports. Atmos Environ. 2015;114:92-101.

2. Roh GS, et al. Efficacy of a traditional Korean medicine, Chung-sang-Bo-hatang, in a murine model of chronic asthma. Int Immunopharmacol. 2005;5: 427-36. https://doi.org/10.1016/j.intimp.2004.09.036.

3. Kim JY, et al. Standardized herbal formula PM014 inhibits radiation-induced pulmonary inflammation in mice. Sci Rep. 2017;7:45001. https://doi.org/10. 1038/srep45001.

4. Lee $\mathrm{H}$, et al. Herbal formula, PM014, attenuates lung inflammation in a murine model of chronic obstructive pulmonary disease. Evid Based Complement Alternat Med. 2012;2012:769830. https://doi.org/10.1155/ 2012/769830.

5. Jung KH, et al. The standardized herbal formula, PM014, ameliorated cigarette smoke-induced lung inflammation in a murine model of chronic obstructive pulmonary disease. BMC Complement Altern Med. 2013;13:219. https://doi.org/10.1186/1472-6882-13-219.

6. Jung KH, et al. The effects of the standardized herbal formula PM014 on pulmonary inflammation and airway responsiveness in a murine model of cockroach allergen-induced asthma. J Ethnopharmacol. 2014;155:113-22. https://doi.org/10.1016/j.jep.2014.04.029.

7. Kim KH, et al. A standardized herbal extract PM014 ameliorates pulmonary fibrosis by suppressing the TGF-beta1 pathway. Sci Rep. 2018;8:16860. https://doi.org/10.1038/s41598-018-35320-8.

8. Food \& Administration, D. Guidance for Industry: Estimating the maximum safe dose in initial clinical trials for therapeutics in adult healthy volunteers. (2005) Available at: view.

9. Kowalska M, Kocot K. Short-term exposure to ambient fine particulate matter (PM2,5 and PM10) and the risk of heart rhythm abnormalities and stroke. Postepy Hig Med Dosw (Online). 2016;70:1017-25.

10. Akther T, Ahmed M, Shohel M, Ferdousi FK, Salam A. Particulate matters and gaseous pollutants in indoor environment and association of ultra-fine particulate matters (PM1) with lung function. Environ Sci Pollut Res Int. 2019;26:5475-84. https://doi.org/10.1007/s1 1356-018-4043-2.

11. Karottki DG, et al. Indoor and outdoor exposure to ultrafine, fine and microbiologically derived particulate matter related to cardiovascular and respiratory effects in a panel of elderly urban citizens. Int J Environ Res Public Health. 2015;12:1667-86. https://doi.org/10.3390/ijerph120201667.

12. Karottki DG, et al. Cardiovascular and lung function in relation to outdoor and indoor exposure to fine and ultrafine particulate matter in middle-aged subjects. Environ Int. 2014;73:372-81. https://doi.org/10. 1016/j.envint.2014.08.019.

13. Lagorio $\mathrm{S}$, et al. Air pollution and lung function among susceptible adult subjects: a panel study. Environ Health. 2006;5:11. https:/doi.org/10.1186/ 1476-069X-5-11.
14. Olsen $Y$, et al. Vascular and lung function related to ultrafine and fine particles exposure assessed by personal and indoor monitoring: a cross-sectional study. Environ Health. 2014;13:112. https://doi.org/10.1186/1476-069X-13-112.

15. Shin D, et al. Gene expression profile of PM014 of immortalized mouse lung epithelial cells in response to the effect of PM014 on radiation-induced fibrosis. Orient Pharm Exp Med. 2019;19:107-14. https://doi.org/10.1007/ s13596-018-0350-x.

16. Reynolds CJ, et al. Lung defense through IL-8 carries a cost of chronic lung remodeling and impaired function. Am J Respir Cell Mol Biol. 2018;59:55771. https://doi.org/10.1165/rcmb.2018-00070C.

17. Lappalainen U, Whitsett JA, Wert SE, Tichelaar JW, Bry K. Interleukin-1 beta causes pulmonary inflammation, emphysema, and airway remodeling in the adult murine lung. Am J Respir Cell Mol Biol. 2005;32:311-8. https://doi.org/ 10.1165/rcmb.2004-03090C.

18. Lei $\mathrm{L}$, et al. Th17 cells and IL-17 promote the skin and lung inflammation and fibrosis process in a bleomycin-induced murine model of systemic sclerosis. Clin Exp Rheumatol. 2016;34(Suppl 100):14-22.

19. Wu Z, et al. Effects of carbon ion beam irradiation on lung injury and pulmonary fibrosis in mice. Exp Ther Med. 2013;5:771-6. https://doi.org/10. 3892/etm.2013.881.

20. Aggarwal S, Ghilardi N, Xie MH, de Sauvage FJ, Gurney AL. Interleukin-23 promotes a distinct CD4 T cell activation state characterized by the production of interleukin-17. J Biol Chem. 2003;278:1910-4. https://doi.org/ 10.1074/jbc.M207577200.

21. Iwakura Y, Ishigame $H$. The IL-23/LL-17 axis in inflammation. J Clin Invest. 2006;116:1218-22. https://doi.org/10.1172/JCI28508.

\section{Publisher's Note}

Springer Nature remains neutral with regard to jurisdictional claims in published maps and institutional affiliations.

\section{Ready to submit your research? Choose BMC and benefit from:}

- fast, convenient online submission

- thorough peer review by experienced researchers in your field

- rapid publication on acceptance

- support for research data, including large and complex data types

- gold Open Access which fosters wider collaboration and increased citations

- maximum visibility for your research: over $100 \mathrm{M}$ website views per year

At BMC, research is always in progress.

Learn more biomedcentral.com/submissions 